\title{
Awakening sleeping beauty: production of propionic acid in Escherichia coli through the sbm operon requires the activity of a methylmalonyl-CoA epimerase
}

Ricardo Axayacatl Gonzalez-Garcia', Tim McCubbin ${ }^{1}$, Annalena Wille², Manuel Plan', Lars Keld Nielsen ${ }^{1}$ and Esteban Marcellin ${ }^{1 *}$

\begin{abstract}
Background: Propionic acid is used primarily as a food preservative with smaller applications as a chemical building block for the production of many products including fabrics, cosmetics, drugs, and plastics. Biological production using propionibacteria would be competitive against chemical production through hydrocarboxylation of ethylene if native producers could be engineered to reach near-theoretical yield and good productivity. Unfortunately, engineering propionibacteria has proven very challenging. It has been suggested that activation of the sleeping beauty operon in Escherichia coli is sufficient to achieve propionic acid production. Optimising E. coli production should be much easier than engineering propionibacteria if tolerance issues can be addressed.
\end{abstract}

Results: Propionic acid is produced in E. coli via the sleeping beauty mutase operon under anaerobic conditions in rich medium via amino acid degradation. We observed that the sbm operon enhances amino acids degradation to propionic acid and allows E. coli to degrade isoleucine. However, we show here that the operon lacks an epimerase reaction that enables propionic acid production in minimal medium containing glucose as the sole carbon source. Production from glucose can be restored by engineering the system with a methylmalonyl-CoA epimerase from Propionibacterium acidipropionici $(0.23 \pm 0.02 \mathrm{mM})$. 1-Propanol production was also detected from the promiscuous activity of the native alcohol dehydrogenase (AdhE). We also show that aerobic conditions are favourable for propionic acid production. Finally, we increase titre 65 times using a combination of promoter engineering and process optimisation.

Conclusions: The native sbm operon encodes an incomplete pathway. Production of propionic acid from glucose as sole carbon source is possible when the pathway is complemented with a methylmalonyl-CoA epimerase. Although propionic acid via the restored succinate dissimilation pathway is considered a fermentative process, the engineered pathway was shown to be functional under anaerobic and aerobic conditions.

Keywords: Propionic acid, Methylmalonyl-COA epimerase, Propionibacterium acidipropionici, Escherichia coli

\section{Background}

In 2012, the US Department of Energy identified propionic acid (PA) as one of the top 30 building blocks to be

\footnotetext{
*Correspondence: e.marcellin@uq.edu.au

${ }^{1}$ Australian Institute for Bioengineering and Nanotechnology,

The University of Queensland, Brisbane, QLD 4072, Australia

Full list of author information is available at the end of the article
}

produced biologically due to its versatility, significance, and the potential for large-scale biological production [1]. PA is a colourless, oily-compound used as a preservative in cereals and animal feeds. Recently, PA applications have expanded to include uses in the textile, dye, drugs, cosmetic and plastic industries [2]. In 2014, the global market for PA was estimated to be USD 1.07 billion with a total volume of 400,000 tonnes but is expected to reach 
USD 1.55 billion by 2020 [2]. PA is currently produced from petrochemical processes. However, consumers are asking for sustainable alternatives. Biological production of PA addresses many sustainability concerns including reduced energy demand as well as being sourced biologically, a desirable attribute in the food industry [3].

PA can be produced biologically through two main native metabolic pathways, the Wood-Werkman cycle of propionibacteria $[4,5]$ and the acrylate cycle of clostridia [6]. Native PA producers, such as propionibacteria, can produce PA as their primary fermentation product achieving high yields. However, these organisms exhibit slow growth, require fastidious nutrient media for growth and lack reliable tools for metabolic engineering. As a result, rational design of native PA producers remains challenging. Only a few examples exist in the literature and these typically result in modest improvements and occur in lower producing native producers that are easier to engineer, such as $P$. shermanii $[7,8]$. Furthermore, these improved strains are still inferior to the best native producers. Heterologous production of PA represents an attractive alternative to overcome limitations in metabolic engineering of native producers and offers a valuable tool to test rational hypotheses that cannot be tested in native producers due to our inability to engineer them [6].

Escherichia coli is a robust microorganism. The heterologous production of organic acids and alcohols by $E$. coli has proven to be a suitable option as evidenced by the commercial success of succinate production [9] by Requette, Bioamber, Reverdia and Myriad [10, 11]; 1,3-propanediol (PDO) by DuPont Tate \& Lyle [12-14]; and 1,4-butanediol (BDO) by Genomatica [15-17]. Amongst the many products that have been produced in $E$. coli, PA was first produced in E. coli by Kandasamy et al. [6] using the acrylate pathway. More recently, several investigations have reported PA production using the silent native operon known as the sleeping beauty mutase, $s b m$ [18-22]. The $s b m$ operon encodes four enzymes, three of them allegedly able to complete a succinate dissimilation cycle: methylmalonyl-CoA mutase (ScpA), biotin-independent methylmalonyl-CoA carboxylase $(\mathrm{ScpB})$, and propionyl-CoA:succinate $\mathrm{CoA}$ transferase (ScpC) (Fig. 1) [23]. The fourth gene in the operon $(\operatorname{argK})$ corresponds to a membrane-bound ATP kinase, and its role in the cycle has not yet been elucidated.

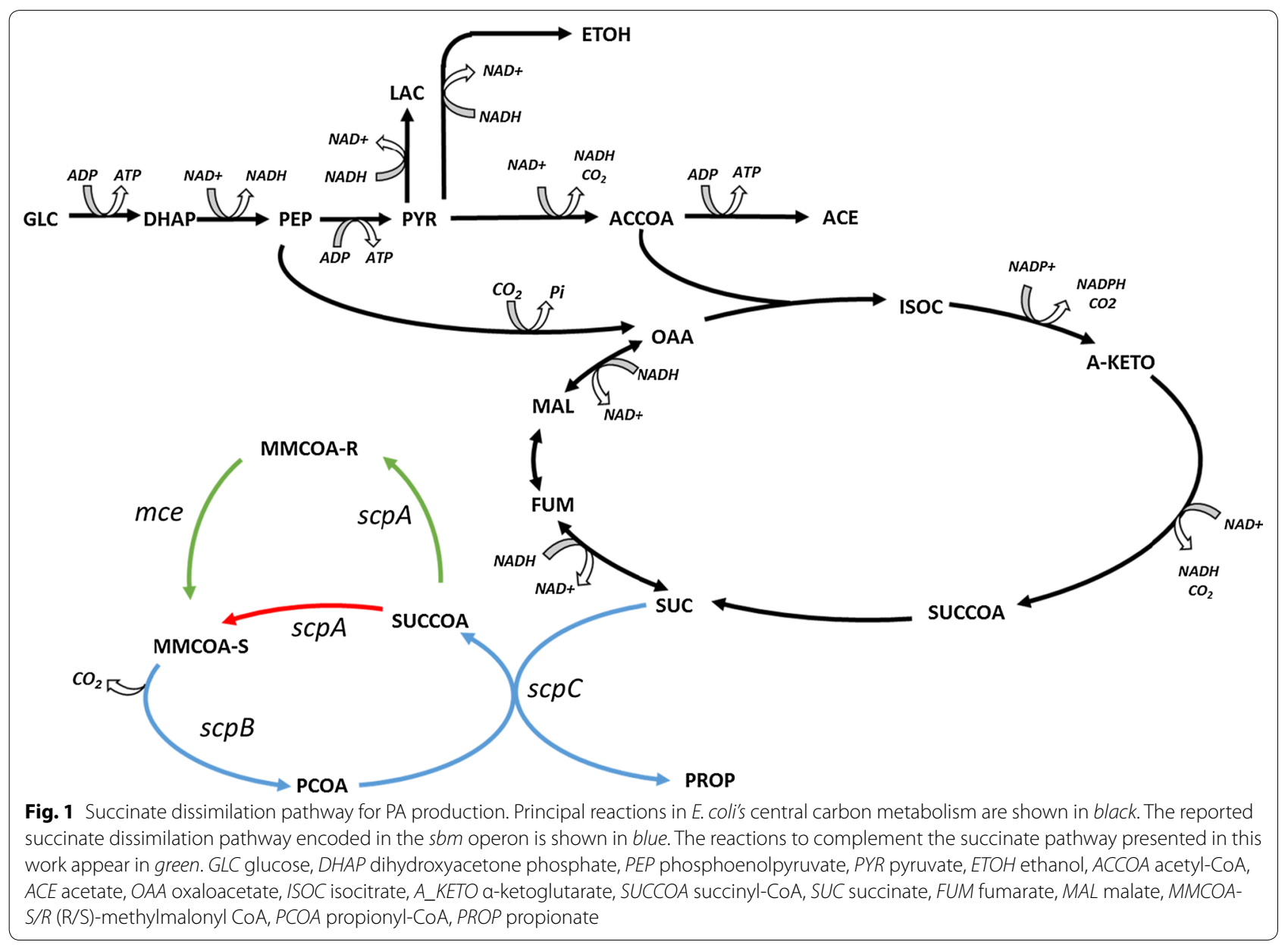


PA production in E. coli expressing the operon [18-22] indicates that ScpA, ScpB and ScpC are sufficient to form the cycle (Fig. 1, red). Indeed, in studying the kinetics of the enzymes in vitro, Haller et al. coupled ScpA (formerly $\mathrm{Sbm})$ to ScpB and observed the two-step conversion of succinyl-CoA into propionyl-CoA [23]. However, this step is not obvious given that methylmalonyl-CoA decarboxylases are reported to act on the (S)-form of methylmalonyl-CoA [23], whereas the mutase in E. coli has been shown to produce the (R)-form [24]. In agreement with Kannan et al. [24], Dayem et al. [25] confirmed that ScpA catalyses the stereospecific conversion of (R)-methylmalonyl-CoA into succinyl-CoA. As such, an additional enzymatic step-an epimerase-would be required to complete the cycle from succinyl-CoA into PA to make the silent operon functional (Fig. 1). Hence, we set out to determine whether the additional epimerase step was required.

We used an in silico metabolic reconstruction to evaluate the feasibility of using the reported succinate dissimilation cycle encoded in the $s b m$ operon for PA production. In silico results show that PA can be produced only when the operon is active and the methylmalonyl-CoA decarboxylase is assumed to be active on the (R)-methylmalonyl-CoA enantiomer. However, our experimental results indicate that for PA to be produced, an additional epimerase is required. Introduction of the methylmalonyl-CoA epimerase from Propionibacterium acidipropionici enabled PA production, from sugar as the sole carbon source, under anaerobic and aerobic conditions.

\section{Methods}

\section{In silico analysis}

The genome-scale model $i J O 1366$ for E. coli K12 MG1655

[26] was used for in silico simulations. Flux balance analysis was performed using the COBRA Toolbox 2.0.5 [27] and MATLAB R2014a. Reactions were deleted from the model by setting the reaction upper and lower bounds to zero. The lower maintenance bound was set to zero for non-growth related simulations. Finally, a PA transporter was added to allow the exchange of PA between the cytoplasmic and periplasmic compartments. All simulations were performed on minimal media with glucose as a sole carbon source assuming anaerobic conditions.

\section{Strains and plasmids}

The full list of strains and plasmids can be found in Table 1. E. coli strains BL21 (DE3), and K12MG1655seq + were obtained from ATCC. E. coli strain DH5-alpha (BIOLINE) was used for regular cloning and fermentations.

\section{Construction of plasmids}

pET28_sbm The $5.6 \mathrm{~kb}$ region containing the $s b m$ operon was PCR amplified from E. coli K12-MG1566seq+ strain using primers sbmF1 and sbmR1 (Table 2). The PCR

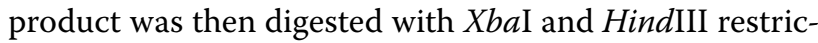
tion enzymes and cloned into the $\mathrm{XbaI}$ and HindIII sites in pET28a+. Confirmation primers listed in Table 2 were used to verify assembly.

pMA_mce The methylmalonyl-CoA epimerase gene sequence (PACID_19260) [28] from P. acidipropionici was codon optimised using the "one codon-one amino acid" method in the online tool OPTIMISER [29]. The optimised sequence was renamed mce and introduced in a synthetic operon consisting of a T7 promoter, a strong ribosomal binding site (RBS), the coding sequence, an additional stop sequence TAA, and a T7 terminator. The designed operon was chemically synthesised (GeneArt, LifeTechnologies) and inserted in a pMA-derived plasmid.

Table 1 Bacterial strains and plasmids used

\begin{tabular}{|c|c|c|}
\hline Strain/Plasmid & Description & Reference \\
\hline Escherichia coli BL21 (DE3) & Expression host & Bioline \\
\hline Escherichia coli DH5a & Cloning and expression host & Bioline \\
\hline Escherichia coli MG1655 & DNA template & $\operatorname{CGSC}^{\mathrm{a}} 7740$ \\
\hline pET28a+ & Cloning vector & LifeTechnologies \\
\hline pBR322 & Cloning vector & LifeTechnologies \\
\hline pMA_mce & pMA derived plasmid. Amp ${ }^{R} P_{T 7}-P_{\text {nar }}-m c e-t_{T 7}$ & LifeTechnologies \\
\hline pET28_sbm & pET28a+ derived plasmid. $K_{a n}{ }^{R}-P_{T 7}-s b m-t_{T 7}$ & This work \\
\hline pET28_sbm-mce & pET28a+ derived plasmid. $K_{a n}{ }^{R}-P_{T 7}-s b m-m_{c e}-t_{T 7}$ & This work \\
\hline $\mathrm{pBRP}_{\mathrm{BAD}}$ & pBR322 derived plasmid Amp $\mathrm{A}^{\mathrm{R}}$. araC- $\mathrm{P}_{\mathrm{BAD}}$ & This work \\
\hline $\mathrm{pBRP}_{\mathrm{BAD} \_} s b m$ & pBR322 derived plasmid Amp ${ }^{R}$. araC-P BAD $-s b m$ & This work \\
\hline $\mathrm{pBRP}_{\mathrm{BAD} \_}$sbm-mce & pBR322 derived plasmid Amp ${ }^{R}$. araC- $P_{B A D}$-sbm-mce & This work \\
\hline
\end{tabular}

a Purchased from the Coli Genetic Stock Centre (CGSC) 
Table 2 Primers

\begin{tabular}{|c|c|c|}
\hline Primer name & Sequence & Description \\
\hline sbmF1 & $\begin{array}{l}\text { CCTTAAGTCTAGAAGGAGAAAACCGATGTCTAACGTGCAGG } \\
\text { AG }\end{array}$ & Forward primer for sbm region amplification \\
\hline sbmR1 & $\begin{array}{l}\text { GCATGCCAAGCTTGCGGCCGCACTAGTTTATTAACCCAGC } \\
\text { ATCGAGCC }\end{array}$ & Reverse primer for sbm region amplification \\
\hline$P_{B A D} F 1$ & GATATCAATCGATTCTAGATTATGACAACTTGACGGC & Forward primer for mce gene amplification \\
\hline$P_{B A D} R 1$ & $\begin{array}{l}\text { GATATCAAAGCTTGCGGCCGCTTATTACATCGGTTTTCTCCT } \\
\text { ACTAGTAGCTCGAATTCCCAAAAAAAC }\end{array}$ & Reverse primer for mce gene amplification \\
\hline $\mathrm{CP}_{\mathrm{BAD}-\mathrm{F}}$ & TTCTCATGTTTGACAGCTTATCATCGATTC & Confirmation forward primer for PBAD region insertion in pBR322 \\
\hline $\mathrm{CP}_{\mathrm{BAD}-\mathrm{R}}$ & CACGGTGCCTGACTGCGTTAG & Confirmation reverse primer for PBAD region insertion in pBR322 \\
\hline cPET-sbmF1 & CGAGCCCGATCTTCCCCATC & Confirmation forward primer for sbm region insertion in pET38a+ \\
\hline cPET-sbmR1 & TGGTCCACGGTTGGGCGG & Confirmation reverse primer for sbm region insertion in pET38a+ \\
\hline cPET-sbmF2 & GCGCCCGCACTATCATTG & Confirmation forward primer for sbm region insertion in pET38a+ \\
\hline cPET-sbmR2 & ATCCGGATATAGTTCCTCCTTTCAGC & Confirmation reverse primer for sbm region insertion in pET38a+ \\
\hline c_sbm-mceF1 & CCATGTTGATCACAGCGAAC & Confirmation forward primer for mce gene insertion in plasmid pET_sbm \\
\hline C_sbm-mceR1 & GTATTTCGGGTGCAGGAAGA & Confirmation reverse for mce gene insertion in plasmid pET_sbm \\
\hline
\end{tabular}

pET28_sbm-mce The mce gene was PCR amplified from the plasmid pMA_mce using the primers mceF1 and mceR1. The PCR product was digested using $X b a \mathrm{I}$ and HindIII and cloned into the SpeI and HindIII sites in pET28_sbm-mce. Confirmation primers listed in Table 2 were used to verify assembly.

$p B R P_{B A D}$ sbm-mce The araC-P $\mathrm{P}_{B A D}$ region was PCR amplified from the plasmid pKD46 with primers $\mathrm{P}_{\mathrm{BAD}} \mathrm{F} 1$ and $\mathrm{P}_{\mathrm{BAD}} \mathrm{R} 1$, digested with ClaI and HindIII and cloned into the ClaI and HindIII sites in pBR322 to build plasmid $\mathrm{pBRP}_{B A D}$. The sbm-mce fragment was released from pET28_sbm-mce by digestion with XbaI-HindIII and the fragment retrieved from a $1 \%$ agarose gel, purified and cloned at the SpeI-HindIII sites in the plasmid $\mathrm{pBRP}_{B A D}$. Confirmation primers listed in Table 2 were used to verify assembly.

PCR reactions were performed using Phusion DNA Taq polymerase (New England Biolabs). All PCR products and DNA fragments were purified using QIAGEN PCR Purification kit according to the manufacturer instructions. For the recovery of a DNA digestion product, DNA was loaded onto an agarose $1 \%$ gel, and the desired fragment was recovered using QIAGEN MinElute gel recovery kit following the manufacturer's instructions. Ligations were performed using T4 DNA ligase at $16{ }^{\circ} \mathrm{C}$ for $16 \mathrm{~h}$. Colony PCR was carried out to verify that the operon was in-frame using the primers listed in Table 2. The sequence was confirmed by Sanger sequencing (AGRF, Australia).

\section{Media composition and fermentations}

Yeast extract and bacto-tryptone were obtained from BD Diagnostics Systems (Franklin Lakes, NJ). All other media components were purchased from Sigma-Aldrich
Co. (St. Louis, MO). Three different culture media were used: complex LB medium $(10 \mathrm{~g} / \mathrm{L}$ yeast extract, $5 \mathrm{~g} / \mathrm{L}$ bacto-tryptone, $5 \mathrm{~g} / \mathrm{L} \mathrm{NaCl}, \mathrm{pH} 7.0$; sterilized by autoclaving); complex SOC medium (20 g/L bacto-tryptone, $5 \mathrm{~g} / \mathrm{L}$ yeast extract, $0.6 \mathrm{~g} / \mathrm{L} \mathrm{NaCl}, 0.5 \mathrm{~g} / \mathrm{L} \mathrm{KCl}, 0.952 \mathrm{~g} / \mathrm{L}$ $\mathrm{MgCl}$, 1.204 MgSO4, 3.6 g/L glucose, $\mathrm{pH} 7.0$; glucose and $\mathrm{MgSO} 4$ were filter sterilized and supplied to the medium after being autoclaved); and a modified M9 mineral medium $\left[1.5 \mathrm{~g} / \mathrm{L} \mathrm{KH}_{2} \mathrm{PO}_{4}, 4.34 \mathrm{~g} / \mathrm{L} \mathrm{K}_{2} \mathrm{HPO}_{4}, 0.4 \mathrm{~g} / \mathrm{L}\right.$ $\left(\mathrm{NH}_{4}\right)_{2} \mathrm{SO}_{4}, 20 \mathrm{~g} / \mathrm{L}$ glucose, $0.31 \mathrm{~g} / \mathrm{L} \mathrm{MgSO} 4 \cdot 7 \mathrm{H} 2 \mathrm{O}$, $1.5 \mathrm{~mL} / \mathrm{L}$ vitamins solution, $1.5 \mathrm{~mL} / \mathrm{L}$ trace elements solution, $\mathrm{pH}$ 7.0; medium was autoclaved; glucose and MgSO $4 \cdot 7 \mathrm{H}_{2} \mathrm{O}$ were autoclaved separately]. Trace elements solution $\left(27 \mathrm{~g} / \mathrm{L} \mathrm{FeCl} \cdot 6 \mathrm{H}_{2} \mathrm{O}, 2 \mathrm{~g} / \mathrm{L} \mathrm{ZnCl} 2 \cdot 4 \mathrm{H}_{2} \mathrm{O}\right.$, $2 \mathrm{~g} / \mathrm{L} \quad \mathrm{CaCl}_{2} \cdot 6 \mathrm{H}_{2} \mathrm{O}, 2 \mathrm{~g} / \mathrm{L} \quad \mathrm{Na}_{2} \mathrm{MO}_{4} \cdot 2 \mathrm{H}_{2} \mathrm{O}, 1.9 \mathrm{~g} / \mathrm{L}$ $\mathrm{CuSO}_{4} \cdot 5 \mathrm{H}_{2} \mathrm{O}, 0.5 \mathrm{~g} / \mathrm{L} \mathrm{H}_{3} \mathrm{BO}_{3}, 100 \mathrm{~mL} \mathrm{HCl}$ ) and vitamins solution $(0.42 \mathrm{~g} / \mathrm{L}$ riboflavin, $5.4 \mathrm{~g} / \mathrm{L}$ pantothenic acid, $6 \mathrm{~g} / \mathrm{L}$ Niacin, $1.4 \mathrm{~g} / \mathrm{L}$ pyridoxine, $0.06 \mathrm{~g} / \mathrm{L}$ biotin, $0.04 \mathrm{~g} / \mathrm{L}$ folic acid, $10 \mathrm{mg} / \mathrm{L}$ thiamine, $0.27 \mathrm{mg} / \mathrm{L}$ cobalamin) were filter sterilized and then supplemented to the media.

Serum bottle fermentations Recombinant E. coli strains were streaked on LB agar plates with antibiotics (Ampicillin $100 \mu \mathrm{g} / \mathrm{mL}$ ) and incubated for $16 \mathrm{~h}$ at $37^{\circ} \mathrm{C}$. A single colony was picked and used to inoculate a $250 \mathrm{~mL}$ baffled flask with $50 \mathrm{~mL}$ of minimal media plus antibiotics. The overnight culture was used to inoculate a $160 \mathrm{~mL}$ serum bottle containing $100 \mathrm{~mL}$ of minimal media plus antibiotics. Arabinose $(10 \mathrm{mM})$ and IPTG $(1 \mathrm{mM})$ were added to the cultures where indicated. Serum bottles were flushed with $\mathrm{N}_{2}$ for 10 min before inoculation and incubated in an orbital shaker at $30{ }^{\circ} \mathrm{C}$ and $200 \mathrm{rpm}$. Samples were taken regularly. Optical density (OD) was measured at $600 \mathrm{~nm}\left(\mathrm{OD}_{600}\right)$ before samples were filtered and stored at $-80{ }^{\circ} \mathrm{C}$ for HPLC analysis. Where indicated, media 
was supplemented with amino acids valine, isoleucine or threonine ( 20 mM).

Bioreactor fermentation Recombinant E. coli strains were streaked on LB agar plates plus antibiotic (Ampicillin $100 \mu \mathrm{g} / \mathrm{mL}$ ) and incubated for $16 \mathrm{~h}$ at $37^{\circ} \mathrm{C}$. A single colony was picked and used to inoculate a $250 \mathrm{~mL}$ baffled flask containing $50 \mathrm{~mL}$ of minimal medium plus antibiotics. The culture was grown overnight in a shaking incubator at $37^{\circ} \mathrm{C}$ and $200 \mathrm{rpm}$ and used to inoculate flasks containing $250 \mathrm{~mL}$ of minimal medium plus antibiotics and arabinose $(10 \mathrm{mM})$. The volume of inoculum was adjusted depending on the desired initial $\mathrm{OD}_{600}$. All fermentations were performed in duplicate in $400 \mathrm{~mL}$ stirred tank DasGip reactors ( $250 \mathrm{~mL}$ operation volume). Temperature and $\mathrm{pH}$ were maintained at $30{ }^{\circ} \mathrm{C}$ and 7.0, respectively. $\mathrm{pH}$ was controlled by the addition of a $4 \mathrm{~N}$ $\mathrm{NaOH}$ solution. Prior to inoculation, the medium was flushed with $\mathrm{N}_{2}$ for 20 min. After inoculation, $\mathrm{N}_{2}$ was top-sparged at a constant rate. For aerobic conditions, dissolved oxygen (DO) was maintained at $80 \%$ of saturation using a cascade control linking airflow and agitation speed. Initial flow was set at $10 \mathrm{~L} / \mathrm{h}$. Samples were regularly taken, and optical $\mathrm{OD}_{600}$ was monitored every $3 \mathrm{~h}$. Samples were filtered and stored at $-80^{\circ} \mathrm{C}$ for HPLC analysis.

\section{HPLC analysis}

Organic acids, carbohydrates, and alcohol were quantified by ion-exclusion chromatography using an Agilent 1200 HPLC system and an Agilent Hi-Plex H column $(300 \times 7.7 \mathrm{~mm}$, PL1170-6830) with a guard column (SecurityGuard Carbo-H, Phenomenex PN: AJO-4490). Sugars and alcohols were monitored using a refractive index detector (Agilent RID, G1362A), set on positive polarity and optical unit temperature of $40{ }^{\circ} \mathrm{C}$. Organic acids were monitored either with RI and/or UV at $210 \mathrm{~nm}$ (Agilent MWD, G1365B). $30 \mu \mathrm{L}$ of the sample was injected onto the column using an autosampler (Agilent HiP-ALS, G1367B), and column temperature kept at $40{ }^{\circ} \mathrm{C}$ using a thermostatted column compartment (Agilent TCC, G1316A). Analytes were eluted isocratically with $14 \mathrm{mM} \mathrm{H}_{2} \mathrm{SO}_{4}$ at $0.4 \mathrm{~mL} / \mathrm{min}$ for $50 \mathrm{~min}$. Chromatograms were integrated using ChemStation software (REV: B.03.02). A previously reported method [18] was also used for comparison.

\section{Protein extraction, trypsin digestion, and identification}

Samples $(2 \mathrm{~mL})$ were collected from the reactor before anaerobic induction and $1 \mathrm{~h}$ after induction. Samples were centrifuged at $4{ }^{\circ} \mathrm{C}, 17,000 \times g$ for $20 \mathrm{~min}$. The pellet was resuspended in $300 \mu \mathrm{L}$ of BugBuster MasterMix solution (Novagen), and intracellular proteins were recovered according to the supplier's instructions.
Protein quantification was performed with a 2D-Quant kit (GE Healthcare). Protein extracts were stored at $-80{ }^{\circ} \mathrm{C}$ before trypsin digestion. Trypsin digestion was performed as described previously [30]. Reverse-phase chromatography was used to clean the digested peptide mixtures using C-18 Zip Tip eluting with $70 \%$ acetonitrile $(\mathrm{v} / \mathrm{v})$. Residual acetonitrile was removed by vacuum centrifugation (Eppendorf, Hamburg, Germany) and peptides resuspended in $0.1 \%$ formic acid before analysis. Peptide identification was performed using LC-MS/MS (AB Sciex 5600, Ontario, Canada). The LC system was equipped with a Vydac MS C18 300- $\AA$, $150 \mathrm{~mm} \times 0.3 \mathrm{~mm}$ column (Grace Davison Discovery Sciences, Deerfield, IL) operated at $30{ }^{\circ} \mathrm{C}$ with a $0-80 \%$ acetonitrile gradient (in $0.1 \%$ formic acid) for $105 \mathrm{~min}$ at a flow rate of $3 \mu \mathrm{L} / \mathrm{min}$ as described in [31]. Protein Pilot 4.2 software (Applied Biosystems, Foster City, CA) was used to identify all proteins. The mass tolerance values for precursor ions and fragment ions were set to the default values of the Paragon search algorithm and trypsin was specified as the digesting protease. The complete genome sequence for $E$. coli K-12 MG1655 was used as sequence database with the addition of the sequence of the optimised gene for the methylmalonyl-CoA epimerase from $P$. acidipropionici. Hits were considered positive when at least two peptides with more than six residues and $90 \%$ confidence were detected.

\section{Results}

\section{In silico analysis}

The genome-scale model, iJO1366, predicts that PA can be natively produced The E. coli GEM, iJO1366 [26] was used to test the native metabolism of E. coli for PA biosynthesis. The model predicts glucose is catabolised to acetate, ethanol, and formate in a molar ratio of 1:1:2.1 during anaerobic growth (Table 3). Traces of succinate (about $1 \%$ of the total acetate produced on a mole basis) were also produced as a result of lysine and methionine biosynthesis. The original model only permits sodiumdriven import of PA. Since PA is permeable to the $E$. coli membrane [32], we added an export mechanism. The addition of the transporter enables PA production. Based on the pKa of PA, the transporter chosen for modelling was a proton symport. The model predicts conversion of succinate to PA through the $s b m$ operon. PA production is energetically favourable given that succinate transport utilises a proton antiport mechanism. Additional simulations using the parsimonious assumption predicted a significant redistribution of fluxes through the central carbon metabolism: acetate, ethanol, formate and propionate produced at a ratio of 1:0.8:1.9:0.2 (S1, Table 3). Furthermore, the solution space shows that when the objective function is set to maximise for maintenance, 2.5 
Table 3 Overall Estimated Yields (mmol)

\begin{tabular}{lll}
\hline & Wild type $^{\mathbf{a}}$ & $\mathbf{S 1}^{\mathbf{b}}$ \\
\hline Biomass & 0.2323 & 0.2331 \\
Acetate & 8.2337 & 8.2661 \\
$\mathrm{CO}_{2}$ & 0 & 0 \\
Ethanol & 8.1936 & 6.1550 \\
Formate & 17.3023 & 15.3765 \\
Glucose & -10 & -10 \\
$\mathrm{O}_{2}$ & 0 & 0 \\
Propionate & 0 & 2.0708 \\
Succinate & 0.0770 & 0
\end{tabular}

a Original model including energetic parameter changes (removal of the polyphosphate kinase reaction), maximised for growth under the parsimonious FBA assumption

b Addition of the propionate symport transporter maximised for growth rate under the parsimonious FBA assumption showing predicted propionate production using the $s b m$ operon

ATP/glucose can be yielded from producing acetate, ethanol, and formate in a 1:1:2 ratio or acetate, formate, and propionate in a 1:1:1 ratio. This simulation suggests that E. coli may produce PA without energetic penalty using a functional $s b m$ operon.

The maximum theoretical yields of $P A$ is $0.85 \mathrm{C}-\mathrm{mol} / \mathrm{C}$ mol glucose The model was used to calculate the maximum theoretical yields for PA with and without the $s b m$ reactions. When the reactions encoded in the $s b m$ operon are present in the model, E. coli utilises a combination of the pentose phosphate and the Entner-Doudoroff pathways as well as the TCA cycle with glyoxylate bypass to source additional reduced cofactors for PA production. Succinate is produced through the phosphoenolpyruvate carboxylase and the dicarboxylic branch of the TCA cycle, allowing for a net PA production of $\sim 0.85$ $\mathrm{C}$-mol/C-mol glucose. The ratio drops to $\sim 0.33 \mathrm{C}-\mathrm{mol} /$ C-mol glucose (0.67 mol PA per mole glucose) when the cycle is inactive, forcing PA production through the energy intensive synthesis and subsequent degradation of threonine.

\section{Heterologous PA production}

The native sbm operon cannot produce $P A$ in minimal medium To determine if the expression of the $s b m$ operon was enough for the production of PA in vivo, we reproduced results from $[20,21]$ using a plasmid expression system controlled by the T7 promoter (pET28a $\mathrm{sbm}$ ) in complex media. PA production was measured after fermenting cells in serum bottles using the same conditions described previously [19-21]. The authors suggest that a high starting $\mathrm{OD}_{600}$ results in high PA titers and they showed that above $10 \mathrm{OD}_{600}$ units, changes in the PA/1-propanol titers were not significant. Thus, 10 $\mathrm{OD}_{600}$ units were used. While PA was detected, the levels were far lower than the previously reported and substantial production of lactate was observed. Table 2 shows the final fermentation products for the batch fermentation in serum bottles. Biomass production was higher in complex media $(0.54 \mathrm{~g} / \mathrm{L})$ compared to minimal media $(0.33 \mathrm{~g} / \mathrm{L})$; the major fermentation product was lactate in both conditions $(\sim 30 \mathrm{mM})$. PA was only detected in complex media $(0.34 \pm 0.02 \mathrm{mM})$. Ethanol production was similar in both conditions $(\sim 11 \mathrm{mM})$, however the acetate to ethanol ratio was nearly $1: 2$, compared to the expected 1:1 ratio. That could be associated to a stress response.

To validate our results, a sample at the highest PA concentration was compared using two HPLC methods (Additional file 1: Figure S1). The first method, described in [19], runs for $20 \mathrm{~min}$ and displayed a ghost peak coeluting with PA (Additional file 1: Figure S4). To resolve the peaks, the second method runs for $50 \mathrm{~min}$ with retention times for PA and 1-propanol at $\sim 28.1 \mathrm{~min}$ and $\sim 41.4 \mathrm{~min}$, respectively. This method resolved the ghost peak co-eluting with PA, and careful evaluation of the HPLC data showed that only one of the two peaks aligned with the PA standard. The total amount of PA estimated was considerably lower when using the long method (Table 4). Notably, the ghost peak was only present when complex medium was used. No changes in the final concentration of organic acids were observed even after $80 \mathrm{~h}$ and lactate was produced. 1-Propanol was detected below the limit of quantitation level.

Co-expression of the sbm operon with an epimerase leads to PA production in minimal medium PA and 1 -propanol were only produced in complex medium (Table 4) suggesting that PA precursors are derived from amino acids catabolism rather than glucose. The model assumes that ScpA converts succinyl-CoA into

Table 4 Fermentation products for E. coli BL21 (DE3) harbouring plasmid pPET28_sbm

\begin{tabular}{|c|c|c|c|c|c|c|c|c|c|}
\hline & Glucose $^{a}$ & Pyruvate & Succinate & Lactate & Formate & Acetate & Propionate & Ethanol & Biomass $^{b}$ \\
\hline Mineral medium & $22.93 \pm 2.75$ & $1.10 \pm 0.07$ & $1.88 \pm 0.09$ & $30.90 \pm 3.39$ & $11.66 \pm 0.89$ & $5.78 \pm 0.32$ & ND & $11.10 \pm 0.28$ & $0.33 \pm .04$ \\
\hline Complex medium & $26.49 \pm 2.54$ & $0.64 \pm 0.04$ & $1.17 \pm 0.10$ & $33.59 \pm 4.03$ & $15.31 \pm 0.68$ & $7.47 \pm 0.73$ & $0.34 \pm 0.02$ & $11.56 \pm 0.64$ & $0.54 \pm .08$ \\
\hline
\end{tabular}

Data correspond to the average of two replicates. All concentration are reported in mM. ND: not detected or below the limit of detection

a Data reported correspond to total glucose consumed out of $100 \mathrm{mM}$

b Biomass is reported in $\mathrm{g} / \mathrm{L}$ 
(S)-methylmalonyl-CoA, the substrate for ScpB (Additional file 2), whereas experimental data suggests ScpA converts succinyl-CoA into (R)-methylmalonyl-CoA [24, 25] (Fig. 1). To investigate if the native succinate dissimilation pathway is restricted by the conversion of the (R)-methylmalonyl-CoA to the (S)-enantiomer, the methylmalonyl-CoA epimerase gene (mce) from $P$. acidipropionici was co-expressed (pET28_sbm-mce).

A strain harbouring both the $s b m$ operon and the epimerase was grown on minimal medium (Table 5). Growth was observed for $24 \mathrm{~h}$, and glucose consumption continued for $48 \mathrm{~h}$ at which point $\mathrm{pH}$ had dropped to $5.22 \pm 0.28$. In all four replicates, PA was produced at a concentration of $0.23 \mathrm{mM}$. 1-Propanol was detected below the limit of quantification of the HPLC method.

To verify that the simultaneous expression of the epimerase and the $s b m$ operon genes lead to PA production in minimal media, E. coli strain DH5- $\alpha$ was transformed with a plasmid containing the sbm operon $\left(\mathrm{pBRP}_{\mathrm{BAD}} \mathrm{sbm}\right)$ and a plasmid containing both the $s b m$ operon and mce gene ( $\left.\mathrm{pBR}_{\mathrm{BAD}} \mathrm{sbm-mce}\right)$. Batch cultures were induced from the beginning with arabinose $(10 \mathrm{mM})$ and proteins were extracted from samples taken at the beginning and the end of the fermentation as described elsewhere [33]. Proteins were identified using nano-LC-MS after trypsin digestion (Fig. 2). PA was only detected in cultures harbouring plasmid $\mathrm{pBR} \mathrm{P}_{\mathrm{BAD} \_} \mathrm{sbm}$ mce $(0.5 \mathrm{mM})$. Peptides corresponding to all enzymes of the $s b m$ operon were identified in both cultures (data not shown) and seven peptides from Mce were identified in cultures harbouring plasmid $\mathrm{pBRP} \mathrm{BAD}_{\mathrm{BA}} \mathrm{sbm}$-mce (Fig. 2c). The comparative expression of $\mathrm{pBRP}_{\mathrm{BAD} \_} \mathrm{sbm}$ and $\mathrm{pBRP} \mathrm{BAD}_{\mathrm{BAD}} \mathrm{sbm}$-mce, as shown by the presence of the Mce peptides after induction illustrates that the expression of $m c e$ is required for propionate production from the $s b m$ operon.

The use of a medium strength promoter $\left(P_{B A D}\right)$ improved $P A$ production The $\mathrm{T} 7$ promoter was replaced by a medium strength promoter, $\mathrm{P}_{\mathrm{BAD}}$, to test the hypothesis that the metabolic burden caused by the T7 promoter and the adverse effects of IPTG limited cell growth and reduced PA production. The plasmid $\mathrm{pBRP}_{B A D}$ sbm-mce was used to transform the DH5- $\alpha$ strain. Two starting biomass concentrations were tested: low $\mathrm{OD}_{600}(\approx 0.1)$ and high $\mathrm{OD}_{600}(\approx 1.0)$ (Fig. 3). Low starting biomass cultures displayed two times higher growth rates compared to high starting biomass cultures $(0.139 / \mathrm{h}$ vs. $0.059 / \mathrm{h}$ ). However, more biomass was produced in the cultures that started at higher initial biomass $(2.16 \mathrm{~g} / \mathrm{L}$ vs. $1.67 \mathrm{~g} / \mathrm{L}$ ). The final PA titer was three times higher in cultures starting at higher biomass, reaching a final concentration of $6.5 \mathrm{mM}$ compared to $1.79 \mathrm{mM}$. For the high biomass condition, the yield was $22.9 \mathrm{mg} \mathrm{gA}_{\mathrm{P}} / \mathrm{g}_{\text {glucose }}$, and the productivity was $12.0 \mathrm{mg} / \mathrm{L} / \mathrm{h}$ compared to 13.7 $\mathrm{mg}_{\mathrm{PA}} / \mathrm{g}_{\text {glucose }}$ and a productivity of $6.1 \mathrm{mg} / \mathrm{L} / \mathrm{h}$ in the low biomass condition.

1-Propanol and PA were detected from the beginning of the fermentation. In both conditions, 1-propanol was produced steadily during the fermentation, while PA production was delayed at the culture that started at low biomass. In both conditions, the highest 1-propanol concentration $(3.5 \mathrm{mM})$ was reached just before glucose depletion. After this stage, 1-propanol concentration decreased which correspond to a small increase in PA. PA concentration increased in a 2-fold after glucose was depleted at the low biomass conditions. In the cultures that started at high biomass, PA concentration remained around $6 \mathrm{mM}$ after glucose depletion. Formate, acetate, and ethanol were the primary fermentation products with traces of lactate and succinate also detected.

Aerobic cultures enhance PA yield E. coli DH5- $\alpha$ harbouring $\mathrm{pBRP}_{B A D \_}$sbm-mce was grown under aerobic conditions, which would provide a higher available pool of succinyl-CoA as consequence of a highly active TCA cycle [34]. Again two starting biomass concentrations were evaluated (Fig. 4). PA production started after $10 \mathrm{~h}$ and was 1.5 times higher compared to anaerobic conditions. For the low starting OD cultures, cells reached the stationary phase after $20 \mathrm{~h}$. The fermentation was monitored for a total of $50 \mathrm{~h}$ (after $50 \mathrm{~h}$, no changes in biomass concentration were observed). At this point $64 \%$ of total glucose supplied was consumed. Final PA concentration was $9.12 \mathrm{mM}$. The second major fermentation product was $\alpha$-ketoglutarate. Low levels of succinate, lactate, acetate, fumarate and ethanol were produced at less than $2 \mathrm{mM}$. 1-Propanol was not detected in the media. Similarly to the anaerobic conditions, a high initial OD favoured PA production in aerobic conditions. Glucose consumption, PA, and biomass production were higher than the low starting biomass culture (Fig. 4). Stationary phase was reached at $15 \mathrm{~h}$. Compared

Table 5 Fermentation products for E. coli BL21 (DE3) harbouring plasmid pPET28_sbm-mce

\begin{tabular}{lccccccccc}
\hline & Glucose $^{\mathbf{a}}$ & Pyruvate & Succinate & Lactate & Formate & Acetate & Propionate & Ethanol & Biomass $^{\mathbf{b}}$ \\
\hline Mineral medium & $72.01 \pm 3.96$ & $0.76 \pm 0.04$ & $8.11 \pm 0.37$ & $65.03 \pm 2.99$ & $24.15 \pm 1.11$ & $15.16 \pm 0.69$ & $0.23 \pm 0.02$ & $19.37 \pm .92$ & $0.85 \pm 0.04$
\end{tabular}

Data correspond to the average of four replicates. All concentration are reported in $\mathrm{mM}$

a Data reported correspond to total glucose consumed out of $100 \mathrm{mM}$

b Biomass is reported in $\mathrm{g} / \mathrm{L}$ 


\section{a MENFNNDPFACIDHVGYAVKDMDEAIKYHTEVLGFHVLLREKNEGHGVEEAMIATGKRGE ESTVVQLLAPLGEDTTIGKYLAKNKNMIQQVCYRTYDIDKTIATLKERGARFTSEEPSSGTAG SRVIFLHPKYTGGLLIEITEPPAGGMPYKD}
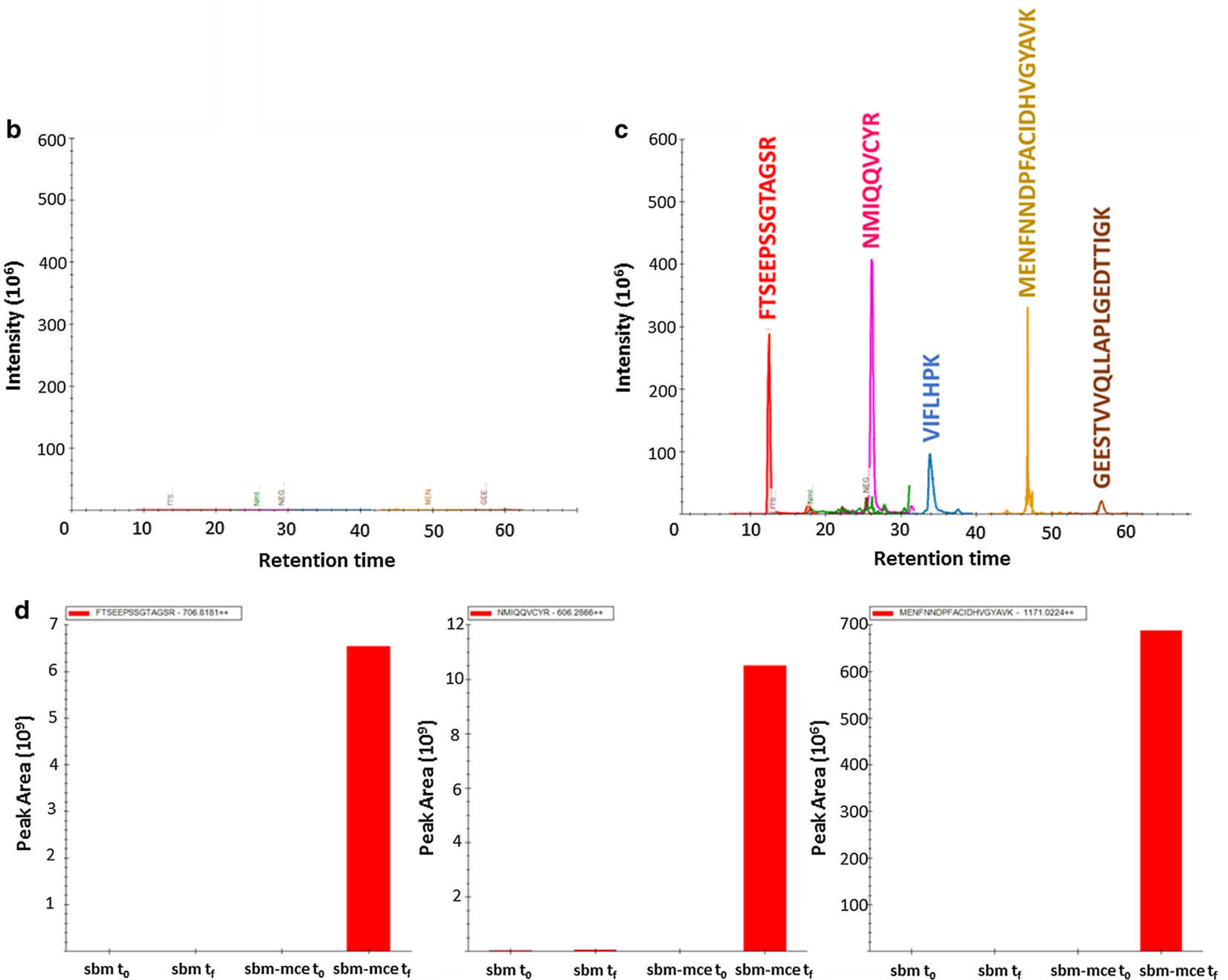

Fig. 2 Protein discovery for the methylmalonyl CoA epimerase. a Protein sequence. The most abundant peptides have been highlighted. $\mathbf{b}$ Chromatograms corresponding to peptide identification for cultures harbouring plasmid pBRP ${ }_{\mathrm{BAD} \_} \mathrm{sbm}$. c Chromatograms corresponding to peptide

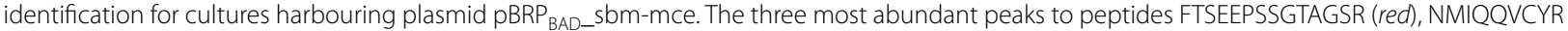
(pink), and MENFNNDPFACIDHVGYAVK (yellow). d Peak areas comparison for the three most abundant peptides in samples taken from cultures at the beginning and the end of the fermentations

to the best results reached in anaerobic conditions, aerobic fermentation increased PA yield by 3-fold from 22.9 $\mathrm{mg}_{\mathrm{PA}} /$ glucose to $70.5 \mathrm{mg}_{\mathrm{PA}} /{ }_{\text {glucose }}$. Productivity was also increased nearly 5 -fold from 6.1 to $28.7 \mathrm{mg} / \mathrm{L} / \mathrm{h}$.

The sbm operon promotes production of PA from amino acid degradation Based on our experimental observations, PA was not produced from glucose when the epimerase is not co-expressed with the operon. We speculated that in complex media, PA was produced from the degradation of amino acids. Complex media contains peptides and amino acids. It is well known that $E$. coli can degrade threonine to PA [35]. In S. erythraea, a genomescale analysis showed that three amino acids (threonine, isoleucine, and valine) could supply propionyl-CoA and (R/S)-methylmalonyl-CoA to enhance erythromycin production [36]. In addition, enzymes that belong to the crotonase superfamily are expected to perform a wide range of reactions [37]. Thus, we tested the potential of the individual expression of the $s b m$ operon to use the aforementioned amino acids. 

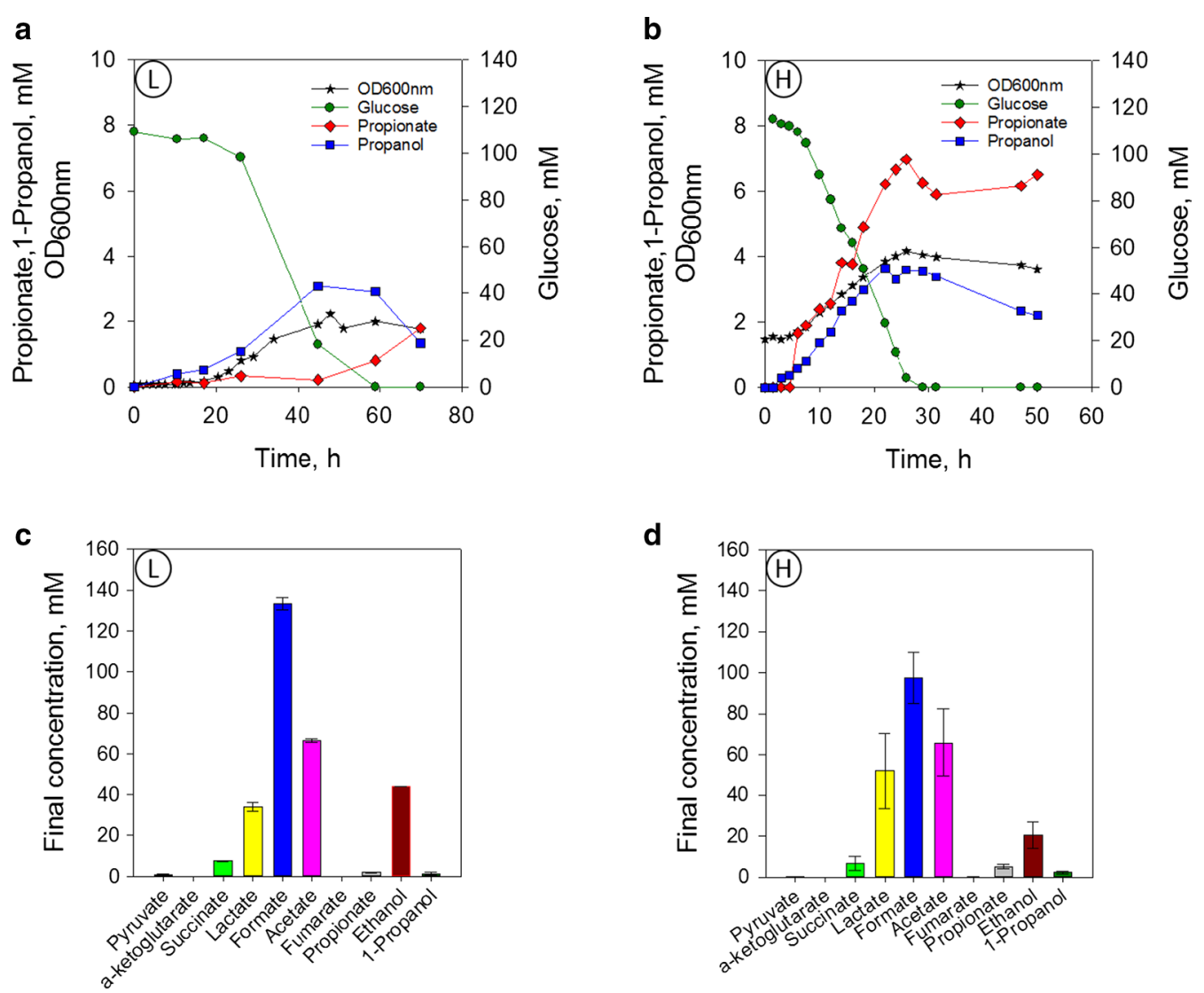

Fig. 3 PA production in $250 \mathrm{~mL}$ DASGIP bioreactor under anaerobic conditions. Arabinose was added to the media from the beginning of the fermentation. Results correspond to the average of two replicates. a Fermentation profile for culture starting at low $O D=0.10(\mathrm{~L})$. $\mathbf{b}$ Fermentation profile for culture starting at high $\mathrm{OD}=1.00(\mathrm{H})$. c Final organic acids concentration for fermentation starting at low $O D=0.10(\mathrm{~L})$. d Final organic acids concentration for fermentation starting at high $\mathrm{OD}=1.0(\mathrm{H})$

Escherichia coli DH5- $\alpha$, harbouring no plasmid (CTRL), the empty plasmid pPBRP $\mathrm{BAD}_{\mathrm{BAD}}$ (PBAD) and plasmid $\mathrm{pBR} \mathrm{P}_{\mathrm{BAD} \_} \mathrm{sbm}(\mathrm{SBM})$ were grown under anaerobic condition in serum bottles in minimal medium. Three media supplemented with valine, isoleucine or threonine were prepared at an initial concentration of $\sim 20 \mathrm{mM}$. The growth profiles for all tested conditions was conserved (Additional file 3). CTRL culture showed the typical mixed-acid fermentation for E. coli. This culture did not show production of PA or 1-propanol, in agreement with all reports regarding the inability of $E$. colis native metabolism to produce PA. Valine supplemented cultures (VAL) consumed less than $6 \mathrm{mM}$ of glucose (Fig. 5) and growth was inhibited as previously reported [38]. The average glucose consumption for the other cultures was $\sim 23 \mathrm{mM}$. After $40 \mathrm{~h}$, propionate was detected in the cultures supplemented with and threonine (THR) but also in the cultures supplemented with isoleucine (ILE) where the $s b m$ operon was expressed. The culture ILE-SBM consumed $4.7 \mathrm{mM}$ of isoleucine, and produced
$0.36 \mathrm{mM}$ of PA and $1.34 \mathrm{mM}$ of 1-propanol. As previously reported [35], there was PA production by native E. coli metabolism from threonine degradation (THR-PBAD) as seen if Fig. 5e (0.29 mM PA, $0.86 \mathrm{mM}$ 1-propanol). However the expression of the $s b m$ operon increased PA and 1-propanol production by 2-fold up to 0.82 and $1.51 \mathrm{mM}$, respectively. Threonine consumption was increased from 0.73 to $2.45 \mathrm{mM}$ (Fig. 5).

\section{Discussion}

Haller et al. [23] suggested that the $s b m$ operon provides an alternative succinate dissimilation pathway to PA. This would require that E. coli mutase (ScpA), unlike other known mutases [24], would produce the (S)-enantiomer of methylmalonyl-CoA directly or that the methylmalonyl-CoA decarboxylase acts on the (R)-enantiomer (Fig. 1). The authors were unable to directly validate this claim as their HPLC method was unable to distinguish between the (R) and (S)-enantiomer of methylmalonyl-CoA. However, they did provide indirect evidence 

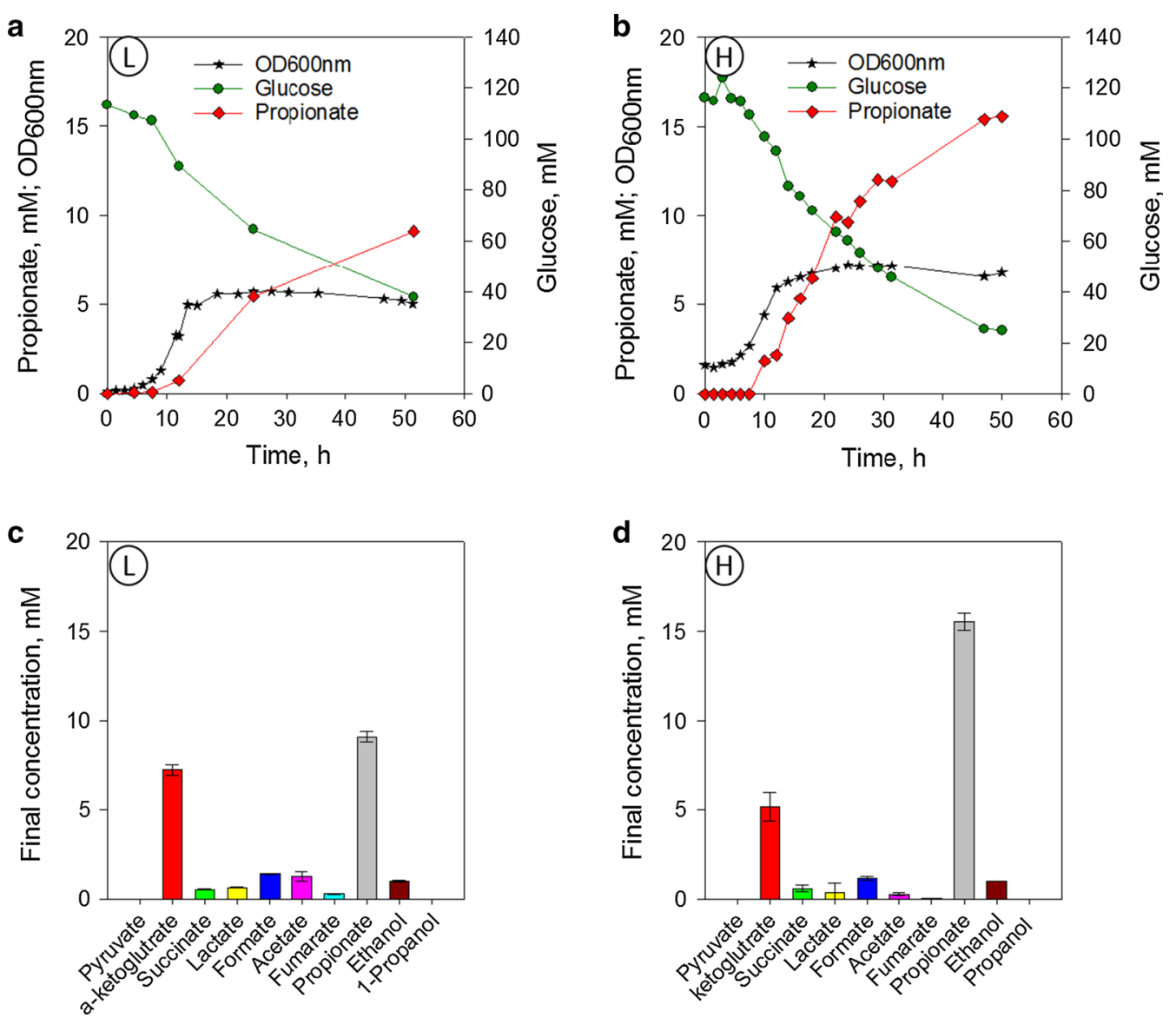

Fig. 4 PA production in $250 \mathrm{~mL}$ DASGIP bioreactor under aerobic conditions. Arabinose was added to the media from the beginning of the fermentation. Results correspond to the average of two replicates. a Fermentation profile for culture starting at low $\mathrm{OD}=0.10(\mathrm{~L})$. $\mathbf{b}$ Fermentation profile for culture starting at high $\mathrm{OD}=1.00(\mathrm{H})$. c Final organic acids concentration for fermentation starting at low $O D=0.10(\mathrm{~L})$. d Final organic acids concentration for fermentation starting at high $\mathrm{OD}=1.0(\mathrm{H})$

through a coupled assay of ScpA and ScpB that it was operational. Other studies have concluded that ScpA is similar to most mutases and can only catalyse the conversion between succinyl-CoA and the (R)-methylmalonyl-CoA enantiomer. Dayem et al. [25] confirmed initial results from Vallari et al. [39] that E. coli does not produce the (S)-methylmalonyl CoA enantiomer [40]. More recently, $\mathrm{Li}$ et al. [22] engineered a succinate producing strain T110 and expressed the $s b m$ operon and the $A B b$ operon from Methylobacterium extorquens AM1 to produce PA. Although a different HPLC method was used, the results from $\mathrm{Li}$ et al. [22] show titres in the same order of magnitude for PA production when the $s b m$ operon is expressed in complex media (Table 2). Further engineered on strain T110 showed a 3-fold increase in PA titre when the $s b m$ operon was expressed. The authors reported increased titres up to $0.49 \mathrm{~mol} \mathrm{PA} / \mathrm{mol}$ glucose when operon $A B b$ was co-expressed. Those results show that the three additional enzyme could perform the epimerase step required to complete the production of PA. Simulations showed that if the native $s b m$ operon was functional, E. coli could ferment sugars into acetate, formate and PA instead of the typical acetate, ethanol, and formate byproduct commonly obtained, as both profiles are energetically equivalent. Nonetheless, when we expressed the $s b m$ operon and cultured cells in minimal media, PA was not produced unless the epimerase was co-expressed. This result supports previous observations $[24,39]$, and shows that the mutase only produces the (R)-enantiomer. Our results cast doubts upon previous works on the expression of the sbm operon for PA production [18-21]. In addition to the epimerase required to complete the succinate dissimilation towards PA, the organic acid could still be produced if a source of (S)methylmalonyl-CoA or propionyl-CoA was available (e.g. from the degradation of amino acids or peptides) [35]. While threonine degradation in $E$. coli is known to produce PA, the expression of the $s b m$-operon doubled PA 

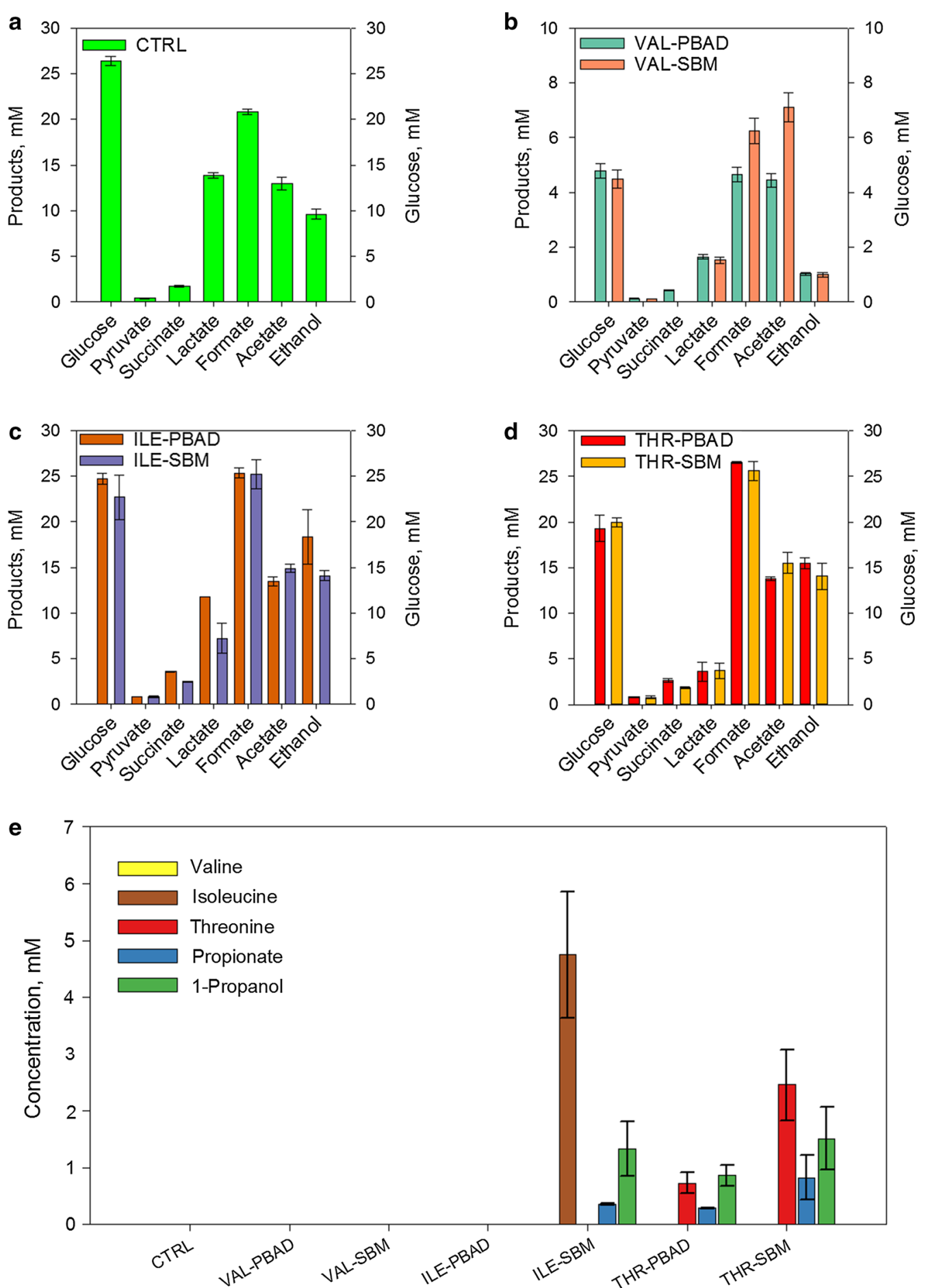

Fig. 5 PA production from amino acids degradation in anaerobic fermentation. Experiments were performed in serum bottles with strains harbouring empty plasmid (PBAD) and the sbm operon genes (SBM). a Total glucose consumption and final organic acids profile for control strain (CTRL, no plasmid). b Total glucose consumption and final organic acid profile for cultures supplemented with valine (VAL). c Total glucose consumption and final organic acids profile for cultures supplemented with isoleucine (ILE). d Total glucose consumption and final organic acids profile for cultures supplemented with threonine (THR). e Total amino acids consumption and final PA and 1-propanol concentration. Data correspond to the average of two replicates 
production. E. coli is natively unable to degrade isoleucine as shown by the E. coli PBAD-ILE culture. However, when the $s b m$ operon is active (SBM-ILE), isoleucine is metabolised. We attribute this feature to the promiscuous activity of the crotonase $(\mathrm{ScpB})$. Our results show that the presence of an unresolved ghost peak as well as the use of complex media have contributed to the PA levels previously reported by other authors [18-22].

After culturing the strain harbouring both the $s b m$ and the mce in minimal medium, the final PA concentration was close to the concentration obtained in complex media. However, the yield observed was lower than the model predictions (Table 3). This was attributed to high lactate production. Lactate is produced as a stress response from the strong T7 promoter [40] as evidenced by the biproduct profile which comprised succinate, ethanol, and lactate. It is well known that the use of a strong T7 promoter is detrimental for metabolic engineering $[41,42]$. The use of the arabinose inducible promoter $P_{B A D}$ offered a double advantage for PA production: on the one hand, it allowed a moderate regulation of gene expression, and at the same time it helped with the catabolic repression of glucose. By enabling biomass accumulation before the production of a toxic metabolite, a 30 -fold increase in production was achieved under anaerobic conditions.

PA production is tightly linked to succinate biosynthesis. It is well accepted that anaerobic $E$. coli fermentation products depend on the balance of reducing power, which results in ethanol, formate, acetate and lactate production as major products [43], leading to a reduction of the succinate and the succinyl-CoA pools. In the case of DH5 $\alpha$ strain, which native metabolism has not been engineered to provide an optimal performance for succinate production under anaerobic conditions, aerobic conditions provide a steady pool of succinate and succinylCoA through a high TCA-flux and the regeneration of cofactors. Here, the shift from anaerobic to aerobic conditions led to a 67-fold increase in PA production from the initial T7 promoter-based system ( 0.23 to $15.53 \mathrm{mM}$ ). Despite such improvement, the production remained modest compared to native producers [44] and the engineered E. coli strain T110 [22]. Production of 1-propanol reached a final concentration of $\sim 4 \mathrm{mM}$ indicating a high promiscuous activity of the AdhE on propionyl-CoA [45].

Under anaerobic conditions 1-propanol seems to be reassimilated after reaching a peak which coincides with glucose depletion and a slight increase in PA production. This is likely the result of a detoxification mechanism [46] induced by 1-propanol. Both low and high biomass conditions showed similar profiles for 1-propanol production, which suggests that cells are able to sense a certain concentration of 1-propanol which triggers a mechanism for detoxification. Our data also shows that the accumulation of organic acids and ethanol play an important role in activating mechanisms of acid and alcohol tolerance [47].

\section{Conclusion}

The presence of a silent operon in E. coli for the production of PA has long intrigued scientists. This pathway, however, is not energetically beneficial compared to lactate and ethanol, which provide a faster and cheaper way to balance redox. Still, PA production can be improved by further engineering of the native metabolism forcing cells to direct carbon towards the production of succinate as described and performed recently [22]. However, the small energetic benefit from avoiding the succinate antiporter is rapidly offset by the requirements to synthesise enzymes for a long catabolic pathway. It is likely that this disadvantage is one of the reasons for which, evolution has silenced the operon. Under aerobic conditions, higher PA production is possible because the TCA cycle enables redox balancing, thus not limiting redox or energy. The toxic nature of PA may be another possible explanation for the pathway inactivation. The inhibitory nature of the propionyl-CoA and succinyl-CoA may play a similar role.

\section{Additional files}

\begin{abstract}
Additional file 1: Figure S1. Chromatogram for the HPLC standards ran in the method reported in [20]. UV detectors signal (A) and RI detector signal (B) are showed. Red line indicates the standards, and blue line indicates the default baseline. Propionate is detected at $17.77 \mathrm{~min}$ and 18.066 min in the UV and RI detector, respectively. Figure S2. Chromatogram for the HPLC standards ran in the method reported in this work. UV detectors signal (A) and RI detector signal (B) are showed. Red line indicates the standards and blue line indicates the default baseline. Propionate is detected at $28.01 \mathrm{~min}$ and $28.396 \mathrm{~min}$ in the UV and RI detector, respectively. Figure S3. Chromatogram for sample taken from an anaerobic culture of E. coli BL21 harbouring plasmid pET28a+_sbm after $48 \mathrm{~h}$. The HPLC method used was the reported in [20]. UV detectors signal (A) and RI detector signal (B) are showed. Blue line indicates the default baseline. Red and green lines are replicates for the same sample. UV detector showed propionate, but this peak does not appear in RI. Instead, there was a signal at 17.18 min. Figure S4. Chromatogram for sample taken from an anaerobic culture of E. coli BL21 harbouring plasmid pET28a+_sbm after $48 \mathrm{~h}$. The HPLC method used was the reported in this work. UV detectors signal (A) and RI detector signal (B) are showed. Blue line indicates the default baseline. Red and green lines are replicated for the sample. UV signal shows that the propionate peak eluting in the short method correspond to two peaks. No propionate was present in the sample. In the RI detector, propionate (28.404 min) elutes closely to another peak (28.42 min). This peak later increases (data not shown in the chromatogram).
\end{abstract}

Additional file 2: Table TS1. Base model with epimerase. Table TS2. Base model without epimerase. Table TS3. Flux distribution.

Additional file 3: Table SA-A. Control Fermentation. Table S3-B. Valine. Table S3-C. Isoleucine. Table S3-D. Threonine. 


\section{Abbreviations}

GLC: glucose; DHAP: dihydroxyacetone phosphate; PEP: phosphoenolpyruvate; PYR: pyruvate; ETOH: ethanol; ACCOA: acetyl-CoA; ACE: acetate; OAA: oxaloacetate; ISOC: isocitrate; A_KETO: a-ketoglutarate; SUCCOA: succinyl-COA; SUC: succinate; FUM: fumarate; MAL: malate; MMCOA-S/R: (R/S)-methylmalonyl-CoA; PCOA: propionyl-CoA; PROP: propionate; PA: propionic acid; OD: optical density; TCA: tricarboxylic acids cycle.

\section{Authors' contributions}

RAG, LKN, and EM planned the experiments. RAG and AW performed all experiments. RAG, MP, TM and EM analysed the data. RAG and EM wrote the manuscript. All authors read and approved the final manuscript.

\section{Author details}

${ }^{1}$ Australian Institute for Bioengineering and Nanotechnology, The University of Queensland, Brisbane, QLD 4072, Australia. ${ }^{2}$ Bielefeld University, Universitätsstraße 25, 33615 Bielefeld, Germany.

\section{Competing interests}

The authors declare that they have no competing interests.

\section{Availability of data and materials}

The datasets during and/or analysed during the current study available from the corresponding author on reasonable request.

\section{Funding}

This work was supported by the Australian Research Council (LP120100517). We acknowledge the support of the University of Queensland and the Mexican Council for Science and Technology (CONACyT) for the scholarship to RAG. EM is a Queensland Government accelerate Fellow.

\section{Publisher's Note}

Springer Nature remains neutral with regard to jurisdictional claims in published maps and institutional affiliations.

Received: 17 April 2017 Accepted: 5 July 2017

Published online: 17 July 2017

\section{References}

1. Werpy T, Holladay J, White J. Top value added chemicals from biomass: I. Results of screening for potential candidates from sugars and synthesis gas. Univ Penn Law Rev. 2004;154(3):477.

2. Market Research Store. Propionic Acid Market for Animal Feed \& Grain Preservatives, Calcium \& Sodium Propionates, Cellulose Acetate Propionate and Other Applications: Global Industry Perspective, Comprehensive Analysis, Size, Share, Growth, Segment, Trends and Forecast, 2014-2020. http://www.marketresearchstore.com/report/propionic-acid-market-foranimal-feed-grain-z39993. Accessed 22 Sep 2016.

3. Dishisha T, Ståhl $\AA$, Lundmark S, Hatti-Kaul R. An economical biorefinery process for propionic acid production from glycerol and potato juice using high cell density fermentation. Bioresour Technol. 2013;135:504-12

4. Thierry A, Deutsch SM, Falentin H, Dalmasso M, Cousin FJ, Jan G. New insights into physiology and metabolism of Propionibacterium freudenreichii. Int J Food Microbiol. 2011;149:19-27.

5. Wood H. Metabolic cycle in the fermentation by propionic acid bacteria. In: Eastabrook RW, Srere P, editors. Current topics cell regulation. New York: Academic Press; 1981. p. 255-87.

6. Kandasamy V, Vaidyanathan H, Djurdjevic I, Jayamani E, Ramachandran KB, Buckel W, Jayaraman G, Ramalingam S. Engineering Escherichia coli with acrylate pathway genes for propionic acid synthesis and its impact on mixed-acid fermentation. Appl Microbiol Biotechnol. 2013;97:1191-200.

7. Wang Z, Ammar EM, Zhang A, Wang L, Lin M, Yang ST. Engineering Propionibacterium freudenreichii subsp. shermanii for enhanced propionic acid fermentation: effects of overexpressing propionyl-CoA: succinate CoA transferase. Metab Eng. 2015;27:46-56.
8. Wang Z, Lin M, Wang L, Ammar EM, Yang ST. Metabolic engineering of Propionibacterium freudenreichii subsp. shermanii for enhanced propionic acid fermentation: effects of overexpressing three biotin-dependent carboxylases. Process Biochem. 2015;50(2):194-204.

9. Meng J, Wang B, Liu D, Chen T, Wang Z, Zhao X. High-yield anaerobic succinate production by strategically regulating multiple metabolic pathways based on stoichiometric maximum in Escherichia coli. Microb Cell Fact. 2016;15(1):141.

10. Choi S, Song CW, Shin JH, Lee SY. Biorefineries for the production of top building block chemicals and their derivatives. Metab Eng. 2015;28:223-39.

11. Chen X, Zhou L, Tian K, Kumar A, Singh S, Prior BA, Wang Z. Metabolic engineering of Escherichia coli: a sustainable industrial platform for biobased chemical production. Biotechnol Adv. 2013;31(8):1200-23.

12. Wang C, Yoon SH, Jang HJ, Chung YR, Kim JY, Choi ES, Kim SW. Metabolic engineering of Escherichia coli for a-farnesene production. Metab Eng. 2011;13(6):648-55.

13. Burk MJ, Van Dien S. Biotechnology for chemical production: challenges and opportunities. Trends Biotechnol. 2016;34(3):187-90.

14. Nielsen J, Keasling JD. Engineering cellular metabolism. Cell. 2016;164(6):1185-97.

15. Erickson B, Winters P. Perspective on opportunities in industrial biotechnology in renewable chemicals. Biotechnol J. 2012;7(2):176-85.

16. Yim H, Haselbeck R, Niu W, Pujol-Baxley C, Burgard A, Boldt J, Khandurina J, Trawick JD, Osterhout RE, Stephen R, Estadilla J. Metabolic engineering of Escherichia coli for direct production of 1,4-butanediol. Nat Chem Biol. 2011;7(7):445-52.

17. Barton NR, Burgard AP, Burk MJ, Crater JS, Osterhout RE, Pharkya P, Steer BA, Sun J, Trawick JD, Van Dien SJ, Yang TH. An integrated biotechnology platform for developing sustainable chemical processes. J Ind Microbiol Biotechnol. 2015;42:349-60.

18. Dellomonaco C, Rivera C, Campbell P, Gonzalez R. Engineered respirofermentative metabolism for the production of biofuels and biochemicals from fatty acid-rich feedstocks. Appl Environ Micriobiol. 2010;76(15):5067-78.

19. Srirangan K, Akawi L, Liu X, Westbrook A, Blondeel EJ, Aucoin MG, MooYoung M, Chou CP. Manipulating the sleeping beauty mutase operon for the production of 1-propanol in engineered Escherichia coli. Biotechnol Biofuels. 2013;6(1):1.

20. Srirangan K, Liu X, Westbrook A, Akawi L, Pyne ME, Moo-Young M, Chou CP. Biochemical, genetic, and metabolic engineering strategies to enhance coproduction of 1-propanol and ethanol in engineered Escherichia coli. Appl Microbiol Biotechnol. 2014;98(22):9499-515.

21. Akawi L, Srirangan K, Liu X, Moo-Young M, Chou CP. Engineering Escherichia coli for high-level production of propionate. J Ind Microbiol Biotechnol. 2015:42(7):1057-72.

22. Li J, Zhu X, Chen J, Zhao D, Zhang X, Bi C. Construction of a novel anaerobic pathway in Escherichia coli for propionate production. BMC Biotechnol. 2017;17(1):38.

23. Haller T, Buckel T, Rétey J, Gerlt JA. Discovering new enzymes and metabolic pathways: conversion of succinate to propionate by Escherichia coli. Biochemistry. 2000;39(16):4622-9.

24. Kannan SM. Studies on methylmalonyl-CoA mutase from Escherichia coli. Doctoral dissertation, University of Westminster. 2008.

25. Dayem LC, Carney JR, Santi DV, Pfeifer BA, Khosla C, Kealey JT. Metabolic engineering of a methylmalonyl-CoA mutase-epimerase pathway for complex polyketide biosynthesis in Escherichia coli. Biochemistry. 2002;41(16):5193-201.

26. Orth JD, Conrad TM, Na J, Lerman JA, Nam H, Feist AM, Palsson BØ. A comprehensive genome-scale reconstruction of Escherichia coli metabolism. Mol Syst Biol. 2011;7(535):535.

27. Hyduke D, Schellenberger J, Que R, Fleming R, Thiele I, Orth J, Feist A, Zielinski D, Bordbar A, Lewis N, Rahmanian S. COBRA Toolbox 2.0. Protocol exchange. 2011;1-35.

28. Parizzi LP, Grassi MC, Llerena LA, Carazzolle MF, Queiroz VL, Lunardi I, Zeidler AF, Teixeira PJ, Mieczkowski P, Rincones J, Pereira GA. The genome sequence of Propionibacterium acidipropionici provides insights into its biotechnological and industrial potential. BMC Genom. 2012;13(1):562.

29. Puigbo P, Guzman E, Romeu A, Garcia-Vallve S. OPTIMIZER: a web server for optimizing the codon usage of DNA sequences. Nucleic Acids Res. 2007;35(Suppl 2):W126-31. 
30. Wisniewski JR, Zougman A, Nagaraj N, Mann M. Universal sample preparation method for proteome analysis. Nat Methods. 2009;6(5):359-62.

31. Orellana CA, Marcellin E, Schulz BL, Nouwens AS, Gray PP, Nielsen LK. High-antibody-producing Chinese hamster ovary cells up-regulate intracellular protein transport and glutathione synthesis. J Proteome Res. 2015;14(2):609-18.

32. Lee SK, Keasling JD. Propionate-regulated high-yield protein production in Escherichia coli. Biotechnol Bioeng. 2006;93(5):912-8.

33. Lim S, Marcellin E, Jacob S, Nielsen LK. Global dynamics of Escherichia coli phosphoproteome in central carbon metabolism under changing culture conditions. J Proteom. 2015:126:24-33.

34. Shimizu K. Regulation systems of bacteria such as Escherichia coli in response to nutrient limitation and environmental stresses. Metabolites. 2013:4(1):1-35.

35. Simanshu DK, Chittori S, Savithri HS, Murthy MR. Structure and function of enzymes involved in the anaerobic degradation of L-threonine to propionate. J Biosci. 2007;32(2):1195-206.

36. Licona-Cassani C, Marcellin E, Quek LE, Jacob S, Nielsen LK. Reconstruction of the Saccharopolyspora erythraea genome-scale model and its use for enhancing erythromycin production. Antonie Van Leeuwenhoek. 2012;102(3):493-502.

37. Hamed RB, Batchelar ET, Clifton IJ, Schofield CJ. Mechanisms and structures of crotonase superfamily enzymes - how nature controls enolate and oxyanion reactivity. Cell Mol Life Sci. 2008;65(16):2507-27.

38. Leavitt RI, Umbarger HE. Isoleucine and valine metabolism in Escherichia coli XI. K-12 valine inhibition of the growth of Escherichia coli strain. J Bacteriol. 1962;83(3):624-30.
39. Vallari DS, Jackowski S, Rock CO. Regulation of pantothenate kinase by coenzyme A and its thioesters. J Biol Chem. 1987;262(6):2468-71.

40. Baig F, Fernando LP, Salazar MA, Powell RR, Bruce TF, Harcum SW. Dynamic transcriptional response of Escherichia coli to inclusion body formation. Biotechnol Bioeng. 2014;111(5):980-99.

41. Blazeck J, Alper HS. Promoter engineering: recent advances in controlling transcription at the most fundamental level. Biotechnol J. 2013;8(1):46-58.

42. Keasling JD. Manufacturing molecules through metabolic engineering. Science. 2010;330(6009):1355-8.

43. Alam KY, Clark DP. Anaerobic fermentation balance of Escherichia coli as observed by in vivo nuclear magnetic resonance spectroscopy. J Bacteriol. 1989;171(11):6213-7.

44. Luna-Flores CH, Palfreyman RW, Krömer JO, Nielsen LK, Marcellin E. Improved production of propionic acid using genome shuffling. Biotechnol J. 2017;12:1600120. doi:10.1002/biot.201600120.

45. Ammar EM, Wang Z, Yang S. Metabolic engineering of Propionibacterium freudenreichii for $n$-propanol production. Appl Microbiol Biotechnol. 2013;97:4677-90.

46. Nicolaou SA, Gaida SM, Papoutsakis ET. A comparative view of metabolite and substrate stress and tolerance in microbial bioprocessing: from biofuels and chemicals, to biocatalysis and bioremediation. Metab Eng. 2010;12(4):307-31.

47. Warnecke T, Gill RT. Organic acid toxicity, tolerance, and production in Escherichia coli biorefining applications. Microb Cell Fact. 2005;4(1):25.

\section{Submit your next manuscript to BioMed Central and we will help you at every step:}

- We accept pre-submission inquiries

- Our selector tool helps you to find the most relevant journal

- We provide round the clock customer support

- Convenient online submission

- Thorough peer review

- Inclusion in PubMed and all major indexing services

- Maximum visibility for your research

Submit your manuscript at www.biomedcentral.com/submit 